\title{
HOW SOCIAL MEDIA RESHAPES ACTION ON DISTANT CUSTOMERS: SOME EMPIRICAL EVIDENCE
}

\author{
Deborah Agostino, Yulia SIdorova \\ Department of Management Economics and Industrial Engineering, Politecnico di Milano
}

\section{INTRODUCTION}

Social media is a pervasive and continuously growing phenomenon at both individual and organizational level. The number of people with an internet connection and a social media account are continuously growing worldwide (Strauss, 2016). At the same time, organizations are reshaping their structures and processes to make a profitable use of this new digital technology (e.g. Kaplan and Haenlein, 2010; Kietzmann et al., 2011). A central feature of social media is renewed access to vast amounts of real time information that would have been beyond our imagination in the past (e.g. McAfee and Brynjolfsson, 2012; Gandomi and Heider, 2015). A social media account provides an organization with a real time access to masses of information posted by customers in their daily life, without the customers being directly involved (as is the case with customer satisfaction surveys). Any comment posted on social media by any customer from any place becomes a source of knowledge and action for the organization, expanding the realm of its controllable space. In this context, where information is available in real time and for free, organizations are constructing new centres of calculation with a dual purpose. On the one hand, they strive to get information about individual customers to be used for marketing and promotional purposes, and in research and development to anticipate trends and gain customer insights (e.g. He et al., 2013). On the other hand, they are interested in monitoring systems capable of detecting and controlling viral and potentially dangerous messages in real time (e.g. Bonson and Ratkai, 2013). The organization can, in this way, "act at a distance" (Latour, 1987) on its customer, bringing the customer back to the organization in real time. Several studies have discussed the calculative practices that organizations use to act on distant customers (e.g. Vaivio, 1999; Cuganesan, 2008). However, to date, we only have limited knowledge about how social media affects this "action at a distance". We are also addressing the call with respect to "future research needs to consider how these new methods of producing accounting impact upon and influence their use in organisations and the calculative consequences that ensue" (Cuganesan, 2008, p.97).

In this context, the aim of this paper is to investigate how centres of calculation, now emerging in connection with social media, impact on the process of acting on distant customers. Specifically, we are interested in exploring how the distance between the organization and its customer is affected and how knowledge is accumulated within this centre.

These issues are analyzed by relying on the concept of centre of calculation and "action at a distance" (Latour, 1987). The rationale behind this is that, by accumulating knowledge into centres of calculation, it is possible to act at a distance, understood as "to do things in the centres that sometimes make it possible to dominate spatially as well as chronologically the periphery" (Latour, 1987, p. 232). The processes of control and action at a distance are shaped within the organization through the measures flowing into the centre of calculation. From a methodological perspective, we conducted a case study in an Italian telecommunications company which has built a centre of calculation, called monitoring room, to gain real time control over its customers. We used interviews, participant observations and document analyses to explore this centre of calculation in terms of its performative nature, and its role in reshaping the distance between the organization and its customers. We also examined the organizational controversies that emerged when the centre was being configured.

Results show that, in its configuration, the new centre of calculation (i.e. monitoring room) blurred the distinction between centre and periphery, which defines "action at a distance", through a de-centring process whereby social media became a joint centre of calculation involving both the organization and its customers. While acting on the customer in real time, not only is the customer visualized by the organization, 
the opposite is also true, and the organization, in replying to its customers' posts, moves towards them, becoming, in turn, an object to be acted upon by the customer.

A second result is related to the ability of the centre of calculation to enact cycles of accumulation. A characterizing element of a centre of calculation is represented by its ability to accumulate knowledge about a periphery. Social media data has the particular feature of being open, providing also external parties with the possibility to manage the same data and gain the same insights available for the centre. To overcome this 'looseness', social media data can be integrated with traditional data, but this requires cooperation between different organizational units, giving rise to organizational controversies about 'who is the customer'.

These results are unfolded throughout the paper, which is structured as follows. Section two provides the background literature, discussing extant literature about accounting implications derived from the endorsement of social media and the theoretical notion of "action at a distance" and centre of calculation, which have been used to interpret findings. The methodology will be then presented, introducing the centre of calculation in the monitoring room at the company Zeus. Results are then unfolded, together with a discussion about the impact of social media in reshaping action on distant customers.

\section{BACKGROUND LITERATURE}

Social media can be defined as "communication systems that allow their social actors to communicate along dyadic ties" (Peters et. al, 2013: 282). It is not a monolithic concept, given that the term social media refers to a variety of communication systems, including social networks such as Facebook, video sharing platforms such as YouTube and microblogging websites like Twitter (Kaplan and Haenlein, 2010; Kietzmann et al., 2011). Unlike traditional data, social media data has two main features: data is user generated and data is provided in real time (O'Reilly, 2005; Kaplan and Haenlein, 2010).

The first distinctive feature is that social media data is user generated (Kaplan and Haenlein, 2010; Kietzmann et al., 2011), with data flowing from users to companies, rather than from the organization to the users as is usually the case with traditional data. The second distinctive feature concerns the availability of social media data in real time (Kaplan and Haenlein, 2010; Kietzmann et al., 2011; Gruber et al., 2015), given that users can comment on social media whenever and from wherever they want simply by having an internet connection. This feature means that masses of data is available, which is a challenge for companies, in terms of storage capacity and data analysis procedures (McAfee and Brynjolfsson, 2012; Gandomi and Haider, 2015). In this context, several authors have discussed the benefits, opportunities and risks associated with social media data (e.g. Fisher, 2009; Bonson and Ratkai, 2013; Ghiassi et al., 2013; Hea et al., 2013; Blankespoor et al., 2014; Holzinger, 2014; Agostino and Arnaboldi, 2016; Arnaboldi and Coget, 2016).

This section covers the literature behind our investigation. Existent studies on the implications of social media applied to accounting are first discussed, followed by the theoretical perspective of action on distant customers and centres of calculation, which supports the interpretation of our findings.

\subsection{Accounting studies on social media}

Several accounting scholars have investigated the social and organizational dynamics affecting accounting practices in connection with the emergent trend of social media (e.g. Jeacle and Carter, 2011; Scott and Orlikowski, 2012) from a social, political and institutional perspective (Hopwood and Miller, 1994).

An early study in this field was carried out by Jeacle and Carter (2011). They looked at how TripAdvisor builds up systems of trust by using the concept of abstract systems proposed by Giddens (1990). They adopted a particular method, "netnography" (Jeacle and Carter, 2011), to access and then explore the rankings and comments on TripAdvisor. Their main result is that the calculative practices connected to TripAdvisor build up trust. More precisely, the popularity index on TripAdvisor is viewed as an expert system that "converts the numerous individual ramblings on the site into hard and objective fact" (Jeacle and Carter, 2011). This index is, therefore, a calculative practice that enhances trust by offering users the rationality of hard numbers. The implications of this study are discussed with reference to the role of accounting experts. In the digital world of today, information is no longer provided or validated by accountants, but it is self-constructed by the community of online users, blurring the differences between experts and non-experts. While this study provides new insights into the changing role of accounting experts, little is said about the contribution of 
these new practices to "action at a distance". It has been said that the Popularity Index stretches the notion of space, by allowing comparisons to be made between hotels in different locations, and the notion of time, by allowing rankings to evolve over time, which helps in making decisions about where to stay in the future. However, we know very little about how "action at a distance" is performed within this digital landscape. Maintaining the focus on TripAdvisor, Scott and Orlikowski (2012) emphasized the constitutive roles of metrics and calculation applied to hard numbers in reshaping relations of accountability. By exploring the role of TripAdvisor reviews in influencing the practices of hoteliers, they investigated how performance and ranking become "power-charged" when web 2.0 technology comes into play. The Popularity Index provided by TripAdvisor, with a focus on its performative nature, was discussed in connection with the role of experts and the distribution of power. The authors found, in line with the previous study by Jeacle and Carter (2011), that social media redefines the boundaries of expertise, since trust is placed in the crowd rather than in the hands of organizational experts. Conversely, it was found that social media calculative practices redistribute accountability relationships. Individuals on social media are simultaneously both consumers and producers, favouring the diffusion of a collective intelligence that places trust in the crowd and relegates hoteliers to a passive role in these mechanisms. The main implication of this redistribution of accountability to the wisdom of the crowd is that it can lead to ambiguous evaluative criteria since, while TripAdvisor shows all the comments about each user, it obscures the ranking mechanism employed. This study expands our current knowledge on how social media accounting practices perform when more power is assigned to the crowd. However, as the authors underlined, further research is required to study "how and where accountability is performed online" (Scott and Orlikowski, 2012, p. 39). In this paper, we acknowledge the need for such additional investigation, by seeing how "action at a distance" is affected by social media practices.

Suddaby et al., (2015) also explored the performative role of social media calculative practices within institutional and professional domains. By adopting the theoretical lens of institutional work, the authors explored the reconfiguration of the accounting expertise domain when dealing with the introduction of Twitter. Four companies were investigated empirically for the study, which demonstrates that social media professionals, in their work, change the professional domains of accountants in three areas, these being boundary work, rhetorical work and the construction of embedded actors. Boundary work shows that a clear distinction has emerged between the domain of accountants and that of social media experts. Rhetorical work refers to the new language associated to the introduction of social media, reflected in a lack of ethics and norms in the language of social media experts. The construct of embedded actors refers to a new construct for the accountant, that of celebrity accountant, to highlight a particular and marked orientation. In line with the previous studies, this investigation enriches our understanding about professionals, in connection to how the accounting domain is rebuilt by the new social media calculative practices. Little is provided, however, about the implications of these emergent practices on "action at a distance" processes. All previous studies recognize that the emergent social media calculative practices are shaping accounting and accountability, by reconfiguring new organizational roles and positioning, experts and expertise, and accountability-type relationships (Jeacle and Carter, 2011; Scott and Orlikowski, 2012; Suddaby et al., 2015). This paper aims to contribute to this emergent literature by focusing on how centres of calculation, in gathering knowledge from social media, "act at a distance", specifically by examining the action on distant customers. In line with previous studies, our aim is to investigate the performative nature of centres of calculation and so expand the current view of accounting as a social and institutional practice within the social media landscape. Conversely, we draw attention to an aspect that is only partially tackled in the currently available contributions, that of "action at a distance" and the accumulation of knowledge obtained from social media into centres of calculation.

\subsection{Action at a Distance and Centres of Calculation}

This paper is positioned in the school of thought that sees accounting as a social, political and institutional practice (Hopwood and Miller, 1994). According to this view, "accounting is no longer to be regarded as a neutral device that merely documents and reports 'the facts' of economic activity. Accounting is instead seen as a set of practices that affects the type of world we live in, the type of social reality we inhabit, the way in which we understand the choices open to business undertakings and individuals, the way in which we manage and organize activities and processes of diverse types, and the way in which we administer the lives 
of others and ourselves" (Hopwood and Miller, 1994, p. 1). In this sense, accounting has a performative nature, since it constitutes and reconstitutes the economic domain. As Boedker and Chua pointed out: "accounting numbers are no longer seen as passive representations of an unproblematic economic situation but as actors that re-present and actively construct particular realities" (Boedker and Chua, 2013, p. 246).

Building upon the conceptualization of accounting as a social and institutional practice, we start from the notion that accounting numbers can be considered as inscriptions that enable "action at a distance", defined as "to do things in the centres that sometimes make it possible to dominate spatially as well as chronologically the periphery" (Latour, 1987, p. 232). In deciding to dominate the periphery, a "centre of calculation" (Latour, 1987) is built, where knowledge and information are accumulated, helping whoever is at the centre to exert control at a distance on something that can be far away from the centre itself. According to Latour, a centre of calculation allows those at the centre to "be familiar with things, people and events, which are distant" (Latour, 1987, p. 220).

This implies that accounting inscriptions are to be mobilized and gathered into centres of calculation, therefore permitting a periphery to be controlled from a distance. This distance is socially constructed rather than physical. In this context, "centres of calculation do not simply make it possible to traverse existing distances, they also participate in shaping the distances involved. Likewise, practices of control at a distance participate in defining the very distance(s) they cover" (Corvellec et al., 2016, p. 3).

The theoretical concept of action at a distance encompasses two elements of attention: the distinction between a centre and a periphery, and the accumulation of knowledge and power into centres of calculation. The first point, the distinction between a centre and a periphery, also concerns the calculative practices that allow the customer to be moved back to a centre (Cuganesan, 2008). Accounting studies widely acknowledge that distances are socially created (e.g. Robson, 1992; Chua, 1995; Briers and Chua, 2001; McNamara et al., 2004; Quattrone and Hopper, 2005), and the way in which accounting information is constructed creates the distance and dichotomy between a centre (i.e. who controls) and a periphery (who is controlled). In this study, we will investigate "action at a distance" examining the relationship between the centre of calculation, located at the organizational level, and the periphery, represented by the customer. Some studies have investigated the role of calculative practices in shaping the distance between the centre and distant customers. For example, Odgen (1997) explored how, within the UK government's work to privatize the water industry, there was the attempt to make the customer calculable. This study showed that a new set of measurements were emerging in this field, to make customer services calculable and visible to a range of stakeholders. Answering the call for a quantitative knowledge that installs a new calculable space in the name of The Customer, Vaivio (1999) examined the events that led to a UK subsidiary company constructing a "novel, highly flexible calculable space inside the enterprise". The author showed that the customer was made quantifiable through a set of non-financial indicators, rather than through traditional financial measures. A more recent contribution examining the strategies for calculating a customer is that of Cuganesan (2008), who investigated the experience of an Australian financial services organization interested in constructing accounting numbers to quantify customer intimacy. He found that new numbers were constructed starting from external market research, but that this process was in the hands of the marketing people. The paradoxical accounting implication was that higher customer intimacy was quantified through less intimate measures of the customer. These extant contributions highlight the role of accounting in enabling action on distant customers. On this point, however, the way in which social media affects action on distant customers is largely under investigated, providing the rationale for this investigation.

The second issue is related to the accumulation of knowledge and power into centres of calculation. Latour (1987) underlined that every time there is a movement that brings a periphery back to a centre, this generates a cycle of accumulation of knowledge. The accumulation of knowledge about a distant periphery and the accumulation of knowledge about distant objects provides the centre with power that it can use to exert action at a distance. This aspect has been further stressed by Miller and Rose (2010) who acknowledged that "the accumulation of inscriptions in certain locales, by certain persons or groups, makes them powerful in the sense that it confers upon them the capacity to engage in certain calculations and to lay a claim to legitimacy for their plans and strategies because they are, in a real sense, in the know about that which they seek to govern" (p. 283). The performative nature of calculation in affecting power relationships has been also demonstrated through empirical studies. For example, Carmona et al. (2002) carried out an investigation 
on how accounting practices produce the control of space within a factory, showing that "as new space is produced through enclosures, partitioning and coding, new power relationships are constituted" (p. 267). In a similar vein, Quattrone and Hopper (2005) examined the implementation of Enterprise Resource Planning (ERP) practices in two multinational organizations, revealing the performative nature of the ERP configuration in creating multiple loci of control rather than increasing power and centralizing control within the headquarter.

In this study we investigated how "action of a distance", together with its distinctive feature of allowing a centre of calculation to accumulate knowledge about a distant periphery, is affected by social media.

\section{METHODOLOGY}

The empirics of this study were derived from the methodology of a case study conducted on an Italian telecommunications company, here called Zeus for confidentiality reasons. Zeus, with over 50,000 employees, is the main Italian telecoms player. The company opened its first social media account in 2008 on Facebook, and has reached almost two million Facebook likes. It now has a social media presence on most popular platforms, Twitter, YouTube, LinkedIn, Google+ and Instagram, as well as Facebook. We collected data from a variety of sources between February 2014 and November 2015, including interviews, participant observations, internal documents, corporate websites and social media pages (see Table 1):

\section{<Insert Table 1 almost here>}

The first data source consists of the interviews. We interviewed people in charge of managing and using social media data, as well as those receiving the reports generated by the new centre of calculation. We also interviewed people in accounting when they played a significant role in the process of using social media. We conducted a total of 10 interviews (see Table 1), each lasting from between half an hour to one and a half hours. The interviews covered types of social media adopted, reasons behind their adoption, type of social media data collected and relative use, indicators measured within the monitoring room, reporting and targets associated to the new indicators and connected problems and opportunities. We used these interviews to gain a comprehensive preliminary view of how the social media centre of calculation is constructed and its organizational implications for the control process.

Participant observations refer to the empirical evidence we collected during interviews, which were all conducted at the company's headquarters. This meant that we were present during the normal daily running of the monitoring room and its centre of calculation operations. We were also able to take part in informal discussions with all the interviewees and so gain useful insights into how the centre of calculation is affecting "action at a distance". We observed the work of the digital department and the way they routinely monitor and analyse data from social media.

The internal documents we examined relate to social media reports and additional memos and minutes from meetings. The social media reports are the daily, weekly, monthly, quarterly and annual reports about social media, prepared by the digital department and/or social media managers, and delivered to other internal units. We received a sample of each type of report, which helped us in the discussions during interviews. Using these reports, we triangulated the evidence from the interviews with a concrete visualization of how the social media data is constructed. The minutes, notes and memos are additional material collected during interviews meetings on top of the social media reports. These documents include communication plans, editorial reports and internal presentations.

The corporate website is the official online communication channel for Zeus. We browsed through it to gain a preliminary understanding of the company's customers, in terms of its main targets, relationships and level of engagement. This preliminary website analysis supported the identification of questions to include in the interviews.

Finally, social media platforms were analyzed with particular attention to the tone of communication with individuals, the type of communication and frequency of interaction. From these data sources, we looked at the numerical aspects (number of "likes" and/or number of "tweets"), and also the flow of communication, type of messages and reaction of individuals, in order to corroborate the information gained from the interviews. 
The process of data analysis involved first exploring the corporate website and social media platforms. We studied the approach used by the company to manage social media, which informed our discussion with the companies' representatives during the interviews. This also helped us to understand how the organizational actors constructed and used the social media indicators. Seven of the ten interviews were recorded and transcribed verbatim. In the remaining three cases, we were not allowed to take a recording, but two participants took copious notes at the interviews, and reorganized the material immediately after the meeting.

In carrying out data analysis, the empirical material was not codified through software, in order to avoid biases associated with the verbatim transcription of the recorded interviews and the carefully taken notes of the others. We used textual analysis instead, with the authors individually highlighting the emerging themes in open-coded categories, which made it possible to identify broader theoretical themes (Corbin and Strauss, 1990). These earlier themes were subjected to a more selective classification, to endorse the relevant elements of our analysis, these being control, "action at a distance", spatial and temporal dimensions of control. These themes were then cross-referenced once again with the theory and with other data sources, in order to enhance the internal validity and reliability of the case-study material (Denzin, 1978). The triangulation of the insights from the interviews and other data sources with theory (Denzin, 1978; Yin, 2014) supported our exploration into how the emergent centres of calculation affect "action at a distance", which will be discussed below.

\section{ACTION AT A DISTANCE THROUGH SOCIAL MEDIA: EVIDENCE FROM THE FIELD}

\subsection{The configuration of a new centre of calculation: the monitoring room}

In mid-2014, Zeus decided to build a new organizational unit, which it called Data Intelligence Department (DID). Its purpose was to exploit social media data more extensively than before. Until that time, social media channels were used to establish a two-way connection with customers, neglecting, in the main data obtained from social media. In 2014, the cumulated experience on social media meant that the company's top management decided to construct the new unit, which was to be entirely devoted to managing social media data. From an organizational point of view, it was placed under the head of the communications, who had, among other responsibilities, that of managing social media. Zeus appointed the head of the newly formed department from within the company, who commented on this new experience:

\footnotetext{
"After providing social care services for more than five years, we understood that we could use social media data more extensively and gain an insight from every conversation. This implies monitoring our customers' conversations and find out more about them. We set up a virtuous circle: you understand what your customer wants, anticipate their needs and target your offer better. Your customer then has a positive experience, the business improves, they talk about you positively and the cycle repeats". (Head of DID)
}

By setting up this department, the intention within the company was to define a set of calculations to visualize social media customers and help bring them back to the organization:

"We need to be driven by data. Social media data can support us in understanding our customers better but, more importantly, we can use data to make predictions and anticipate trends" (Head of DID).

At the practical level, this translation of the customer was made possible by constructing a centre of calculation, called monitoring room. The monitoring room consists of a set of screens where social mediabased dialogues are shown on eight different screens, together with a set of measures to visualize the individuals on social media immediately, their mood and the topic of discussion. During our meetings with the company, we spent time in this monitoring room with its eight screens. One screen was projecting the overall sentiment score about Zeus in real-time, another was displaying a Twitter live feed, the third, the main news from Rome and Italy, the fourth, a domain ranking of the topics emerging from the individuals' conversations on social media, the fifth one was showing the network and its influencers, the sixth was busy with Facebook, while the seventh and eight screens were used for benchmarking analyses with competitors. 
The measures calculated within this centre include the following: domain ranking, sentiment score, reach, engagement and influencer measures. The measure of domain ranking lists the topics most discussed on social media. The sentiment score assigns a polarity to every comment posted, distinguishing between neutral, positive and negative. The measure of reach indicates the number of people who have seen the social media posts, while that of engagement concerns the activity surrounding a Facebook post or the retweets per tweet on Twitter.

Internal reports were produced to present the monitoring room, describing it and its purposes as follows:

"The monitoring room is a real time monitoring facility, with focus on both on quantitative and qualitative analytics. Its main purpose is to analyze online conversations, trying to conjugate them with offline surveys and research, in order to understand the impact of online conversations on brand reputation and how communication and marketing strategies can be reshaped through these analyses" (Internal report).

The central aspect of the monitoring room is its real-time activity, which means that information on every screen is always updating, with people on social media posting comments, Zeus answering, and the measures of domain ranking, sentiment score, reach, engagement and influencer varying continuously. The main implication about working in real time is the demand for urgency, to answer quickly. The importance of being fast, on top of the need for accurate calculation, was highlighted several times during the interviews:

“We don't define our editorial plan in advance. We draw up our plans in real-time, depending on what is happening on social media" (Head of DID)

Configuring the monitoring room was the biggest challenge for the head of the Digital Department, who saw this centre of calculation as the tangible outcome of his quest to use data and drive all the actions of all the organizational units in the company. Several times, he underlined how this new centre of calculation had accumulated knowledge about their customers, allowing them to find out unexpected elements to be controlled and acted upon:

"We must be able to catch signals from this mass of social media data and integrate this data with other data. The crucial point is to find what we want in all the noise" (Head of DID).

"We need to make predictions to understand, for example, if the customer is ready for a new offer. And we do the same with our competitors. If we monitor how people react to our competitors' offers and products, we can detect what they lack and come up with our own proposals." (Head of Communication)

During our fieldwork, we followed the work carried out by organizational actors in the monitoring room and found two main issues creating tension and controversy that affected action at a distance through social media, connected to the relationship between the centre and the periphery and to the accumulation cycle. These two aspects will be described later.

\subsection{Reshaping Distance and Centre-Periphery Relations}

The main implication of social media for "action at a distance" is clearly that it empowers social media users, and this can significantly affect how the organization acts upon distant customers. A central feature of the monitoring room is its real time activity, which allows an action and reaction to take place between the company and its customers. The importance of providing a quick response to a customer's post was stressed several times, even when this could have a negative effect on data precision:

"We do not need precise numbers about sentiment and influencers. A general perception is enough." (Social Media CRM operator)

Moreover, not only should the response be fast, but it had to be aligned with the mood of the network: 
"We wrap up our plans in real time, depending on what is happening on social media. If the network cries, we should feel the same and cry too" (Head of DID)

This need to be aligned with the mood of the network alongside the urgency to answer customer comments became an aspect employed by social media users to gain importance and be heard by the organization. During the many discussions with the digital department managers, they pointed out several times that the judgments made on the network are also important. It is not simply a matter of replying to a customer, you are evaluated by your customers, and their actions will be affected by your response.

"Customers are demanding when they post on social media. If we post something about a new offer, we never get a comment about the offer but we do get customers complaining about something, from mobile phone services to internet connection, broadband and so on. Anything that has nothing to do with our offer. They expect their problems to be solved there and to receive a prompt reply. This is strategic work for us: we have to be quick, polite and effective in responding, especially as we want to retain our customers" (Social media strategy manager).

Although the initial intention of setting up the monitoring room was to bring the customer to the organization in real time, in practice, the opposite also occurred with the organization moving into the public arena and towards the customer. Within the virtual space of social media, at any given moment, customers post comments and the organization replies, bringing about a real time action-and-reaction process between social media users. This virtual space is visible to everyone and everyone uses it to act at a distance over the other actors.

The organization acts towards its customers, by bringing comments back into their monitoring room. Customers, and social media users more in general, bring comments and posts from the organization and other users back into their realm of action. Social media space becomes, in this way, a joint centre of calculation between the customer and the organization. The organization uses social media to gain information about users, and users judge the organization's response time and quality of response on social media. It becomes a two-way control: while the company tries to control its customers, they, in turn, use social media to judge and assess the organization. This was clear by the decision taken by Zeus to introduce indicators for evaluating the response time for a customer post:

"We have a response time indicator that is used to evaluate our activity. It looks at how long we take before replying to a customer post in minutes. The target value varies from one social media to another. For Facebook, for example, it is 15 minutes, but we expect to bring it down to 10" (Social media CRM operator)

"We have no free evenings, Saturdays or Sundays. It's a full-on process and you need to be on the job" (Social Media Strategy Manager).

In an attempt to control the customer, a further indicator was developed to control the organization's ability to respond quickly. Two aspects of this new virtual social media deserve attention. These are the reduced importance of distinguishing between a centre (i.e. the organization) and a periphery (i.e. the customer) and the blurring of the distance between the centre and the periphery.

On the one hand, the difference between organization and its customers is no longer significant. Everyone in the network has equally importance, and this importance is related to their level of influence in the network. This was made clear by the decision of the organization to introduce a further measure to monitor how quickly it was able to respond to social media messages posted by influencers.

"Every time an influencer posts something, I get an alert, as we must immediately look at the reaction it gets over the network. As it says in the name, the influencer obviously influences the network, so we are interested in controlling and monitoring their activity" (Social Media Strategy Manager) 
"You need to act quickly in the monitoring room, because if the screen shows a complaint made by an influencer, we need to answer straight away. We must manage the risk linked to a particular decision, but we have to do this to avoid the message spreading further" (Head of communication)

These statements highlight the pressure felt by the organization on how it is judged by its customers and the potential virality of negative messages.

On the other hand, "action at a distance" is no longer exerted by the centre towards the periphery, but is a two-way flow. The organization acts at a distance over its customer, while the opposite takes place at the same time, with customers acting at a distance over the organization. This happens when customers, and influencers especially, want to be heard the organization, posting potentially damaging messages:

\footnotetext{
"A famous Italian blogger placed a post on our Facebook page about a problem with her mobile connection. Our operators answered after only a few minutes. The reaction on the network was staggering: other customers were complaining that we had given her preferential treatment over 'normal' customers. The posts went viral, with an impressive number of related comments. We had to apologize for any inconvenient and convince the network that there was no preferential treatment. You have to pay attention to everything when dealing with your customers on social networks" (Social media CRM operator).
}

This active role of customers and their action at a distance on the organization, paradoxically empowered the digital department. It used the virality of these negative messages to underline the importance of taking influencer-related measures and were able to convince the social media opponents in the company about the strategic role of the new centre of calculation:

\begin{abstract}
"You may not trust this measure and you may not believe in the power of social media data, but you cannot escape the reach of network influencers. When a powerful social media user, who may not even be a "traditional customer", posts a negative message about the organization, if this goes viral, it gives a negative image of the organization. The marketing department may very well criticise the network influencer and not look at my reports, but our image will still feel the effect of social media activity" (Head of DID)
\end{abstract}

\title{
4.3 Problematizing Cycles of Accumulation and 'the Customer'
}

The monitoring room was not only affected by the distance between the organization and its customers, but also by how knowledge was accumulated within the centre of calculation, and this did lead to organizational controversy. By relying on social media data, the way knowledge about customers is accumulated refers mainly to measuring the network influencers. This measure had been intended to quantify the relevance of every customer acting on social media:

"We use social network analysis to identify the influencers. This implies first mapping the nodes of the network and then evaluating the density around each node. Higher density implies that there is a community of users connected to our brand" (Data Analyst).

Social network analysis is used to identify the influencers and their distance from the organization is depicted graphically. The greater the distance between the nodes (i.e. the customers) and the organization, the looser the connection between the two. The contrary is also true, the nodes closest to the organization are those that influence the network the most.

Calculating this indicator further contributed to the accumulation of knowledge about customers into the monitoring room's centre of calculation. However, this accumulation cycle generated some issues. The first concerned the eventuality that other actors, including ones from outside the organizational boundaries, could perform the same social media analyses and compute the same social media indicators. This is possible given the openness typical of social media data:

"If you have a Wi-Fi connection and skills in IT and data analysis, you can do the same things. Smart social media users can sometimes carry out these analyses and mine social media data, using this information for their own purposes" (Data Analyst) 
To overcome this problem, the digital department looked for ways to make the organization's accumulated knowledge unique. He tried to achieve this by integrating the data on customers visualized within the monitoring room with more traditional data kept elsewhere in the organization, but this did not work. The two types of customers do not overlap and there was no possibility of linking social media users with the customers stored in our CRM databases:

\begin{abstract}
"What we don't have is a match between the individual on social media and our customer relationships management database. Right now, there is no match. If someone is talking about Zeus on Facebook, I don't even know if they are in our customer relationships management database. We are working on it, but right now we have two separate views: the person on social media and our customers". (Customer Experience Manager, Zeus)

"The real value lies in the connection between social media data and CRM data, because this is the only way to get a 360-degree view of your customer. We analyse people who are talking about Zeus on social media, but we don't know if they are our customers or not". (Head of DID, Zeus)
\end{abstract}

When relying on the knowledge cumulated in the centre of calculation managed by the controlling department, the customer is recognized through an identification number held in the customer relationship management (CRM) database. Hence, the customer is a defined someone who has already purchased goods or services from the organization. On the contrary, when using knowledge gathered in the monitoring room, the outcome is that everyone is talking about the organization on social media, with the additional indication of the importance of whoever is talking, obtained through the network influencer measurement.

This difficulty of matching the customer visualized in the monitoring room with the customer visualized through traditional data sources brought about tensions within the organization concerning what makes a customer valuable:

"The best customer is the network influencer, who may not even be my customer!" (Head of DID)

It follows that the level of activity within the social media network determines the connection and relevance of real and potential customers. In contrast, other units within the organization kept to their more traditional views on customers, whose importance was linked to their contribution to the company's revenue:

"It's not true. The best customer is the one who spends the most" (Head of marketing)

This tension between the organizational units confidently using social media data and the more sceptical ones meant that the social media reports prepared by the digital department were used differently. The sceptical units often dismissed these reports:

"When something new appears to convince me about social media data, then I'Il use this data and I'Il ask for it" (Controller)

Another interesting point was the fluidity of customers visualized in the monitoring room, and this led to further tensions. Every time the influencer measure was applied, new values emerged, with new customers being considered as influencers, since the measure depends on each person's number of connections and level of activity, and this is continuously changing. The value of influencers is therefore fluid and depends on the number of their connections and their links to a given topic of discussion, and this aspect is built into the network. The same customer can be an influencer in one network but not in another. The data analyst once again clarified this point:

"If I set 'youth offers' as a key word, I'Il get this network [showing us the graph]. If I change the time span, look [showing us again], the influencers are different. And the same happens if you change keywords. Every time you send a query to the system, keying in different parameters, you get different network configurations and different influencers" (Data Analyst) 
This fluidity when elaborating the influencers affects the distance between the customer and the organization, which in turn becomes fluid and is determined by connections and level of activity within the social network. Paradoxically, an influencer may not even be a customer, but they affect a company as soon as they talk about it. This results in the increasing of importance of active social media users who may or not be clients of the organization, while others who have frequent transactions with the organization are seen to be of lesser importance. This fluid view of the customers that emerged from the monitoring room was a further bone of contention between the units supporting social media data and those that did not.

\section{DISCUSSION}

The introduction of social media prompted the organization to configure a new centre of calculation, called monitoring room, for gathering knowledge from the periphery, represented by its real and potential customers. Through the monitoring room, the spatial-temporal distance was constructed through real time screens that projected measures relating to domain ranking, sentiment score and network influencers. The monitoring room's configuration, and the steps to bring the customer back into the realm of what the organization is able to control, had two main implications in terms of with how social media affects "action at a distance". These are the blurring of the difference between the centre and the periphery, and the centre's ability to accumulate unique knowledge about the customer. These two insights will be discussed below in connection with extant literature.

\subsection{Blurring the difference between centre and periphery}

A distinctive element of a centre of calculation is that it makes "action at a distance" possible (Latour, 1987). By gathering knowledge in a centre, there is a clear separation between this centre of calculation and a periphery. Social media's distinctive features of working in real time and allowing users to generate content was found to blur the distinction between the centre (the monitoring room) and the periphery (the customer). The actions and reactions on social media between the organization and its customers is brought back to the eight screens in the monitoring room. Everyone can follow the discussions directly through social media channels: customers, and social media users more in general, read, judge and possibly reply to posts, together contributing towards shaping the indicators seen in the monitoring room. While only the digital department has access to the centre of calculation in the monitoring room (with the other units using their reports), social media itself becomes the virtual space where, in a reciprocal process, the organization acts upon the customer and, at the same time, is being acted upon by the customers. In our fieldwork, this was visible with the introduction of a further indicator to monitor the response time to customers' posts, this being an element that the organization felt was used by their customers to judge it. This is where we find the greatest paradox: while the organization wished to achieve control over its customers, it turned out that it was being controlled instead by its customers, leading it to reshape its actions accordingly.

This result has two main implications. On the one hand, social media reshapes "action at a distance" by removing the distinction between centre and periphery. Even though organizations can set up a centre of calculation to gather information about real and potential customers, a de-centring process also takes place through the actions and reactions defining the interaction between the organization and its customers on social media channels. Social media, in this way, became a space with joint control, split between the organization and its customers and blurring the distinction between centre and periphery. This result confirms that distances between organizations and customers are socially created (Robson, 1992; Chua, 1995; Briers and Chua, 2001; McNamara et al., 2004; Quattrone and Hopper, 2005; Cuganesan, 2008), but it adds to extant knowledge with the recognition that this distance is not a one-way path to bring the periphery back to the centre through information gathering cycles. Social media data seems to affect this path, giving rise to two information gathering cycles between a centre and a periphery, and these act upon each other simultaneously, with an ensuing de-centring of the centre of calculation.

On the other hand, this insight into the fuzzy distinction between a centre and a periphery moves forward the extant literature concerned with the accounting implications derived from social media (e.g. Scott and 
Orlikowski, 2012; Suddaby et al., 2015) and, in particular, the risks connected with social media data (Arnaboldi and Coget, 2016). While social media allows organizations to access data of a type not even possible to imagine in the past, during the configuration of new centres of calculation and in the operations that take place there, the distinction between the organization that accumulates knowledge about its customer and the customer who is acted upon is blurred. Social media websites have the potential to be more open spaces, where the organization and its customers share similar levels of relevance and control to each other. Indeed, this raises the prospect of shifts in power in organizational-customer relationships and is an area that future research might investigate.

\subsection{The ability of the centre to accumulate a unique knowledge about customers}

A central feature of a centre of calculation lies in its ability to gather information about a periphery, performing an action at a distance. In our empirical setting, using the centre of calculation of the monitoring room, the organization had the intention of accumulating knowledge about customers by exploiting social media data. Although this was its initial intention, while configuring the monitoring room and operating within, it emerged that the knowledge that was being gathered in the monitoring room was not unique, but could be replicated by others outside the centre and, even more critically, outside the organization's boundaries. This meant posing a question about how social media could contribute towards accumulating a unique set of knowledge within a centre of calculation. Moreover, to counterbalance this "loose" control, social media data can be integrated with traditional data, but this requires cooperation between different organizational units, with all that entails in terms of 'who is the customer'.

This result has two major implications. The first relates to how social media data can contribute to the centre's work of accumulating a unique knowledge about the periphery, further de-centring the point of accumulation. The possibility of duplicating the knowledge being gathered into centres of calculation contributes to extant literature where the benefits associated with social media data and accounting digitalization are being questioned (e.g. Arnaboldi and Coget, 2016; Quattrone, 2016). This study highlights that social media, with its features of real time and openness, allows continuous interactive activity between two parties that control each, assigning them the same importance. Moreover, the knowledge accumulated about distant customers can be replicated, giving someone else the possibility of developing the same insights. Future research needs to investigate how this de-centring and replication of knowledge outside the organization's boundaries can impact on the new emerging professionals, including outside these organizational boundaries, and what their role is in connection with the relationship between organization and customer.

The second implication refers to the organizational issues that emerge when companies attempt to integrate social media data with other data already available, with all the problems about "who is the customer". Organizational conflicts between people with various specialisms in various functions and accountants responsible for acting on a distant periphery has been discussed in extant literature (e.g. Seal et al. 2004; Cuganesan, 2005), and it is clearly recognized that domains between different functions overlap which has all the potential for conflicts about who performs "the accounting stuff" (Cuganesan, 2005). The emergence of social media professionals has been highlighted in more recent studies (e.g. Suddaby et al., 2015), where the point is made that accountants are being pushed aside by the surge in social media, which is firmly in the hands of social media professionals. Our study highlighted these organizational tensions between the former, with their rigid focus on traditional measures and the latter, immersed in social media data. However, in addition to extant literature, our empirical investigation shows that the "accounting" operations overlap between different organizational professionals, and that they can be also performed by customers and others outside the organizational boundaries, if they have some knowledge about social media. Being able to access social media data for free can potentially allow everyone to carry out analyses involving distant peripheries. This result suggests that the accounting domain is expanding, not simply to include social media professionals, but also customers outside the organization's boundaries. Further research can adopt a customer perspective and explore how single customers perform their accounting and action at a distance.

\section{CONCLUDING REMARKS}


With this study, we, as authors, entered into the emerging debate on the implications for the accounting arena of adopting social media extensively in an organization (e.g. Jeacle and Carter, 2011; Scott and Orlikowski, 2012; Quattrone, 2016). By endorsing the view that accounting is a social and institutional practice (Hopwood and Miller, 1994) and examining the concepts of "action at a distance" and centres of calculation (Latour, 1987), we investigated how the centres of calculation connected to social media can impact on "action at a distance". The aspect we explored specifically was how the distance between an organization and its customers comes into play and how knowledge is accumulated within this centre.

The way the centre of calculation had been configured had a bearing on "action at a distance" in two ways. First, one distinctive feature of a centre is that it acts on a distant periphery and this found to be blurred. Because of the chain of action and reaction between the organization and its customers, the organization was not alone in gathering information about distant customers. Customers also accumulated knowledge about the organization, and this, in turn, was perceived to be controlled by its customers. This blurred distinction highlights the fact that a de-centring process was taking place with social media data acting on distant customers.

Second, the knowledge accumulated in the centre was not unique, but could be replicated by users with skills in data analytics. This aspect led to further de-centring, while prompting the organization to combine social media data with other data to gain a unique insight into a distant periphery. The data gathering cycle exploiting social media data differs from that of accumulating information using traditional approaches, meaning that the customers were not visualized in the same way, and this resulted in even more fuss within the organization.

These contributions also provide a major implication for practitioners, this being the vulnerability of social media data. Organizations are increasingly relying on social media analytics, building centres of calculation to manage this new type of data. Our study underlined that the knowledge gained from social media data is often totally unrelated to the traditional information managed by the organization. Additionally, social media analysis does not give the organization unique knowledge, since someone else outside the organization can perform the same analysis using data analytics if they have the right skills (and leverage, therefore, on social media indicators to act upon the organization). This study should be of help to managers entering the social media realm, suggesting that they should carefully consider how to use all these connected social media analysis.

Finally, the limitations of the study also need to be addressed. On the one hand, we relied on a just one case study. This makes it much more difficult to generalize the insights, but their internal validity is ensured by having triangulated the findings. Further research could extend this investigation to other organizations, or even to industries other than telecommunications. On the other hand, we investigated the action on distant customers from the perspective of the organization, although we relied on comments from social media. Future research needs to address both perspectives, not only the view point of the organization examined, but also that of the individual customers and their intentions when acting on social media. 


\section{References}

Agostino, D. and Arnaboldi, M. (2016), "A Measurement Framework for Assessing the Contribution of Social Media to Public Engagement: An empirical analysis on Facebook", Public Management Review, Vol. 18 No.9, pp. 1289-1307.

Arnaboldi, M. and Coget, J.F. (2016), "Social media and business: We've been asking the wrong question", Organizational Dynamics, Vol. 45 No.1, pp. 47-54.

Blankespoor, E., Miller, P. and White, H.D. (2014), "Initial evidence on the market impact of the XBRL mandate", Review of Accounting Studies, Vol. 19.4, pp. 1468-1503.

Boedker, C. and Chua, W.F. (2013), "Accounting as an affective technology: A study of circulation, agency and entrancement", Accounting, Organizations and Society, Vol. 38 No.4, pp.245-267.

Bonson E. and Ratkai M. (2013), "A set of metrics to assess stakeholder engagement and social legitimacy on a corporate Facebook page", Online Information Review, Vol. 37 Iss.5, pp.787-803.

Briers, M. and Chua, W.F. (2001), "The role of actor-networks and boundary objects in management accounting change: a field study of the implementation of activity-based costing", Accounting Organizations and Society, Vol. 26 No.3, pp. 237-270.

Carmona, S., Ezzamel, M. and Gutiérrez, F., (2002), "The relationship between accounting and spatial practices in the factory", Accounting, Organizations and Society, Vol. 27 No.3, pp. 239-274.

Chua, W.F. (1995), "Experts, networks and inscriptions in the fabrication of accounting images: a story of the representation of three public hospitals", Accounting Organizations and Society, Vol. 20, No.2-3, pp. 111-145.

Corbin, J.M. and Strauss, A. (1990), "Grounded theory research: Procedures, canons, and evaluative criteria", Qualitative Sociology, Vol. 13 No.1, pp 3-21.

Corvellec, H., Ek, R., Zapata, P. and Zapata Campos, M.J. (2016), "Acting on distances: a topology of accounting inscriptions", Accounting Organizations and Society,

doi: http://dx.doi.org/10.1016/j.aos.2016.02.005

Cuganesan, S. (2006), "The role of functional specialists in shaping controls within supply networks", Accounting, Auditing \& Accountability Journal, Vol. 19, No.4, pp. 465 - 49.

Cuganesan, S. (2008), "Calculating customer intimacy: accounting numbers in a sales and marketing department", Accounting Auditing and Accountability Journal, Vol. 21 No.1, pp 78-103.

Denzin, N. K., (1978), “The Research Act” (2nd ed.), New York: McGraw-Hill.

Fisher, T. (2009), "ROI in social media: a look at the arguments", Journal of Database Marketing \& Customer Strategy Management, Vol. 16, pp. $189-195$.

Gandomi, A. and Haider, M. (2015), "Beyond the hype: big data concepts, methods and analytics", International Journal of Information Management, Vol. 35, pp.137-144.

Giddens, A., (1990), "The consequences of modernity”, Cambridge: Polity Press.

Ghiassi, M., Skinner, J. and Zimbra, D. (2013), "Twitter brand sentiment analysis", Expert Systems with Applications, Vol. 40 No.16, pp.6266-6282. 
Gruber, D.A., Smerek, R.E., Thomas-Hunt, M.C. and James, E.H. (2015), "The real-time power of Twitter: Crisis management and leadership in an age of social media", Business Horizons, Vol. 58 No.2, pp. 163-172.

He, W., Zha, S., and Li, L. (2013), "Social media competitive analysis and text mining: A case study in the pizza industry", International Journal of Information Management, Vol. 33 No.3, pp. 464-472.

Hea, W., Zha, Sh. and Li, L. (2013) "Social media competitive analysis and text mining: A case study in the pizza industry", International Journal of Information Management, Vol. 33, pp. 464- 472.

Holzinger, A. (2014), "Social Media Mining and Social Network Analysis: Emerging Research", Online Information Review, Vol. 38 No.1, pp. 157-158.

Hopwood, A. and Miller, P. (Eds) (1994), "Accounting as Social and Institutional Practice", Cambridge University Press, Cambridge.

Jeacle, I. and Carter, C., (2011), "In TripAdvisor we trust: Rankings, calculative regimes and abstract systems", Accounting Organizations \& Society, Vol. 36 No.4-5, pp. 293-309.

Kaplan, A. and Haenlein, M. (2010), "Users of the world, unite! The challenges and opportunities of social media", Business Horizons, Vol. 53 No.1, pp. 59-68.

Kietzmann, J. H., Hermkens, K., McCarthy, P., and Silvestre, B. S. (2011), "Social media? Get serious! Understanding the functional building blocks of social media", Business Horizons, Vol. 54, pp. 241-251.

Latour, B., (1987), "Science in action: How to follow scientists and engineers through society", Harvard university press.

McAfee, A. and Brynjolfsson, E. (2012), "Big data: the management revolution", Harvard Business Review, October, pp. 1-9.

McNamara, C., Baxter, J., and Chua, W.F. (2004), "Making and managing organisational knowledge(s)", Management Accounting Research, Vol. 15 No.1, pp. 53-76.

Ogden, S. G., (1997), "Accounting for organizational performance: the construction of the customer in the privatized water industry", Accounting, Organizations and Society, Vol. 22 No.6, 529-556.

O'Reilly, T. (2005), "What is Web 2.0", retrieved from http://www.oreilly.com/pub/a//web2/archive/whatis-web-20.html

Peters, K., Chen, Y., Kaplan, A. M., Ognibeni, B. and Pauwels, K. (2013), "Social Media Metrics - A Framework and Guidelines for Managing Social Media", Journal of Interactive Marketing, Vol. 27, pp. 281298.

Quattrone, P. and Hopper, T. (2001), "What does organizational change mean? Speculation on a taken for granted category", Management Accounting Research, Vol. 12 No.4, pp. 403-435.

Quattrone, P. and Hopper, T. (2005), "A 'time-space odyssey: management control systems in two multinational organizations", Accounting Organizations and Society, Vol. 30, pp. 735-764.

Quattrone, P. (2016), "Management accounting does digital: will the move make it wiser?", Management Accounting Research, Vol. 31, pp. 118-122.

Robson, K. (1992), "Accounting Numbers as "Inscription": Action at a Distance and the Development of Accounting", Accounting, Organizations and Society, Vol. 17 No.7, pp. 685-708. 
Rose, N. and Miller, P. (2010), "Political power beyond the State: problematics of government.", The British journal of sociology, Vol. 61 s1, pp. 271-303.

Scott, S.V. and Orlikowski, W.J., (2012), "Reconfiguring relations of accountability: Materialization of social media in the travel sector", Accounting Organizations and Society, Vol. 37 No.1, pp. 26-40.

Seal, W., Berry, A., and Cullen, J. (2004), "Disembedding the supply chain: institutionalized reflexivity and inter-firm accounting", Accounting, Organizations and Society, Vol. 29 No.1, pp. 73-92

Strauss, J., (2016), E-marketing. Routledge.

Suddaby, R., Bruton, G.D. and Si, S.X. (2015), "Entrepreneurship through a qualitative lens: insights on the construction and/or discovery of entrepreneurial opportunity", Journal of Business Venturing, Vol. 30 No.1, pp. 1-10.

Vaivio, J., (1999), "Examining the quantified customer", Accounting Organizations and Society, Vol. 24, pp. 689-715.

Yin R.K., (2014), “Case study research: Design and methods" (5th ed.), Thousand Oaks, Calif.: Sage. 